\title{
INTERAÇÕES E FORMAÇÃO DE CONCEITOS EM CIÊNCIAS: UM OLHAR PARA AS PESQUISAS BRASILEIRAS À LUZ DO REFERENCIAL TEÓRICO HISTÓRICO-CULTURAL
}

\author{
DANIELA SILVA de LOURENÇO \\ Universidade Federal da Fronteira Sul (UFFS), Campus Cerro Largo, Rio Grande do Sul, Brasil \\ SANDRA MARIA WIRZBICKI \\ Universidade Federal da Fronteira Sul (UFFS), Campus Realeza, Paraná, Brasil
}

\begin{abstract}
REsUMo: O trabalho proposto objetiva apresentar como a produção científica na área de ensino de Ciências e Biologia vem compreendendo a formação conceitual dos alunos e quais interações caracterizam esse processo de aprendizagem. Do ponto de vista metodológico, trata-se de uma pesquisa de natureza qualitativa, com caráter descritivo e bibliográfica. Para a análise dos dados foram usados procedimentos de Análise Textual Discursiva (ATD). A partir da análise foi possível identificar as categorias emergentes Interações no Ensino e aprendizagem de conceitos e $O$ papel da mediação no ensino e aprendizagem de conceitos. Os trabalhos consultados trazem o uso da palavra como principal signo mediador da aprendizagem. As interações mais recorrentes apontadas são as entre professor e aluno, aluno e professor e entre pares.
\end{abstract}

Palavras-chave: Ensino de Ciências e Biologia. Mediação. Desenvolvimento conceitual. Teoria Histórico-Cultural.

\section{INTRODUÇÃO}

Compreender o desenvolvimento conceitual do aluno em sala de aula implica investigar as relações de ensino e aprendizagem, as interações envolvidas nesse processo e o papel preponderante do professor na sistematização das atividades, pois, na perspectiva vigotskiana (VIGOTSKI, 2009), é por meio das interações sociais que o ser humano se desenvolve e se constitui enquanto sujeito.

Ao direcionar o olhar para os estudantes, reconhecemos que esses são sujeitos com vivências, que trazem para a escola uma bagagem de experiências e potenciais a serem lapidados. Cabe ao professor estimular essas potencialidades para o estudante ser um sujeito crítico e ativo na aprendizagem, compreendendo e manifestando "[...] conhecimentos acerca de objetos complexos cuja compreensão muitas vezes requer inter-relações de significados conceituais" (WIRZBICKI; DEL PINO; PANSERA-DE- ARAÚJO, 2019, p. 143).

Tendo formação inicial na área do Ensino de Ciências da Natureza e Biologia e como aporte teórico o referencial Histórico-Cultural proposto por Vigotski (2009), partimos do princípio de que a compreensão conceitual acontece em ambientes sociais 
de interação, em que um adulto, ou alguém em uma fase mais elevada do desenvolvimento, é o responsável por transmitir toda cultura e a aprendizagem por menor que essa possa representar, pressupõe ser significativa. Santos (2007, p. 10) considera que "[...] não há como pensar em um aprendizado eficaz que não passe necessariamente pelo 'sentido', pela significação". Desta forma, Santos (2007) destaca que o estudante, ao atingir um estágio de desenvolvimento conceitual mais avançado, já é capaz de discriminar, generalizar, estabelecer relações e exemplificar.

Para o aluno desenvolver melhor a compreensão conceitual científica, o professor deve criar condições que favoreçam a aprendizagem, pois, para Schnetzler, Silva e Antunes-Souza (2016, p. 15), "[...] os conceitos científicos no contexto escolar são apropriados e reelaborados na interação professor-aluno pela mediação pedagógica". Dessa forma, como compreendemos que cabe ao professor criar tais condições, um bom exemplo é elaborar um planejamento sistematizado de atividades a respeito de uma temática a ser estudada que leve em consideração aspectos históricos, sociais e culturais dos sujeitos. Góes $(1997$, p. 21) considera que "[...] o conceito científico se forma ao ser inserido em relações de níveis de generalidade, num sistema organizado hierarquicamente. Daí ser considerado sistematizado".

Para a sistematização dos conceitos, é importante o olhar do professor para as atividades propostas, para as diferentes metodologias, para estratégias diversificadas de ensino e para a utilização de ferramentas variadas que vão auxiliar o aluno na compreensão dos conceitos. Assim, quanto mais diversificadas as atividades desenvolvidas pelo professor, mais atenção e curiosidade ele poderá atrair do aluno. Para Souza e Maldaner (2012),

[...] o ensino planejado, pensado, adequado e que se põe à frente do desenvolvimento real da criança possibilita que se criem novas funções mentais, pois a criança precisará evoluir seu pensamento ao resolver problemas postos pelo bom ensino, propiciando novas funções mentais (SOUZA; MALDANER, 2012, p. 3).

As funções mentais abrangem também a forma como os sujeitos apropriam-se da aprendizagem dos conceitos estudados. Vigotski (2009) trabalhou com o conceito de "internalização" para explicar como o conhecimento externo, construído em meio social e interacionista, é internamente apropriado e reconstruído pelo sujeito. Já Smolka (2000) atribuiu maior profundidade ao termo, o qual denominou de "apropriação". Nessa mesma linha de entendimento, Silva $(2013$, p. 22) destaca que "[...] a apropriação de conceitos científicos por parte do indivíduo pode levá-lo a se conscientizar dos próprios processos mentais".

Ao trazer essa questão para o Ensino de Ciências e Biologia, na própria Base Nacional Comum Curricular - BNCC, encontramos a seguinte definição: “[...] os conhecimentos conceituais são sistematizados em leis, teorias e modelos. A elaboração, a interpretação e a aplicação de modelos explicativos para fenômenos naturais e sistemas tecnológicos são aspectos fundamentais do fazer científico" (BRASIL, 2017, p. 548). Essas orientações, abordadas na BNCC, são importantes e contemplam direitos e habilidades que cada aluno tem para aprender e atingir níveis de desenvolvimento de 
forma igualitária.

Há de se considerar, ainda, a existência de inter-relações entre conceito científico e espontâneo na aprendizagem conceitual do aluno, em que um exerce influência de si sob o outro. O conceito científico desenvolve-se a partir de um conhecimento espontâneo e este por meio daquele. Segundo Fontana (1997, p. 124), "[...] a relação da criança com o conceito é sempre mediada por outro conceito". São essas relações conceituais entre conceito espontâneo e científico, conduzidas pela mediação de signos e instrumentos, que contribuirão para uma melhor compreensão conceitual do aluno referente ao objeto de aprendizagem.

Nesse sentido, signos e instrumentos são elementos fundamentais defendidos por Vigotski (2009) na mediação da aprendizagem. Nessa perspectiva, Silva (2013) considera que

[...] a utilização dos signos modifica fundamentalmente todos os processos psicológicos. Já a utilização de instrumentos amplia de forma ilimitada a gama de atividades no interior das quais novas funções psicológicas podem operar (SILVA, 2013, p. 13).

Dessa forma, apontamos a relevância deste estudo, pois ao compreendermos as interações em sala de aula é possível avançarmos também na compreensão de como os alunos desenvolvem a significação conceitual a partir de processos mediados. Assim, a pesquisa instiga-nos a buscar respostas para a seguinte questão problematizadora: quais interações são descritas nos trabalhos publicados na Biblioteca Digital Brasileira de Teses e Dissertações (BDTD), no Ensino de Ciências da Natureza e Biologia, na perspectiva Histórico-Cultural e como elas influenciam na compreensão conceitual? Nesse sentido, nosso estudo tem por objetivo investigar como a produção científica na área de Ciências da Natureza e Biologia, na perspectiva Histórico-Cultural, vem compreendendo a formação conceitual dos alunos e quais interações caracterizam esse processo.

\section{AsPeCtOS METODOLÓGICOS}

A presente pesquisa é de abordagem qualitativa com base na proposta de Lüdke e André (1986), com caráter descritivo e do tipo bibliográfica. As pesquisas de abordagem qualitativa são consideradas, pelos autores supracitados, aquelas que visam a produzir e aprofundar compreensões por meio de dados descritivos.

Dessa forma, nesta pesquisa foi realizado um mapeamento de dissertações e teses disponíveis na base de dados da Biblioteca Digital Brasileira de Teses e Dissertações (BDTD), e para a análise a opção se deu pela Análise Textual Discursiva (ATD) proposta por Moraes e Galiazzi (2007). De modo geral, a ATD se trata de uma metodologia de análise de dados e informações de cunho qualitativa, que tem como principal finalidade "[...] produzir novas compreensões sobre os fenômenos e discursos analisados" (MORAES; GALIAZZI, 2007, p. 2).

Para a seleção das dissertações e teses foram utilizados os descritores "Interação" e "Conceitos Científicos no Ensino de Ciências", para que somente trabalhos referentes às temáticas com fundamentação teórica Histórico-Cultural fossem indicados. A busca foi realizada empregando-se o filtro de busca por assunto e usando-se como 
recorte temporal os anos de 2000 a 2020. Ao fazer-se uso do descritor "Interação Ensino de Ciências", foram levantados 77 trabalhos. Desses, apenas sete retratam plenamente a temática de pesquisa "Interações pedagógicas e formação de conceitos no Ensino de Ciências da Natureza e Biologia" numa perspectiva teórica Histórico-Cultural, sendo seis dissertações e uma tese. Para caracterização desses trabalhos, em um primeiro momento foi realizada a leitura de cada um nos resumos e palavras-chave, e, ao identificar um dos descritores, foi feita uma leitura completa do trabalho para encontrar os dois descritores previamente definidos.

De forma semelhante, ao se fazer uso do descritor "Conceitos Científicos" a busca foi realizada por assunto. Para esse descritor foram levantados 35 trabalhos, entre os quais apenas seis abordavam, de fato, a temática "Interações pedagógicas e formação de conceitos no ensino de Ciências da Natureza e Biologia", sendo três dissertações e três teses. Os trabalhos identificados foram organizados numa ordem cronológica de publicação; para aqueles cujos anos se repetiram deu-se prioridade para a ordem do mês de publicação. Os trabalhos são apresentados no Quadro 1.

\begin{tabular}{|c|c|c|}
\hline $\begin{array}{l}\text { Dissertação (D) } \\
\text { Tese (T) }\end{array}$ & Título dos trabalhos & Instituição \\
\hline$D_{1}$ Silva (2004) & $\begin{array}{c}\text { Análise do desenvolvimento de conceitos } \\
\text { científicos sobre a teoria da evolução das espécies } \\
\text { em alunos do Ensino Médio }\end{array}$ & $\begin{array}{l}\text { Universidade } \\
\text { Estadual de } \\
\text { Maringá }\end{array}$ \\
\hline $\mathrm{D}_{2}$ Ribeiro (2008) & $\begin{array}{l}\text { Interações discursivas e elaboração de conteúdos } \\
\text { científicos no Ensino Médio }\end{array}$ & $\begin{array}{l}\text { Universidade } \\
\text { Tecnológica } \\
\text { Federal do } \\
\text { Paraná }\end{array}$ \\
\hline $\mathrm{T}_{1}$ Schroeder (2008) & $\begin{array}{c}\text { A teoria histórico-cultural do desenvolvimento } \\
\text { como referencial para análise de um processo de } \\
\text { ensino: a construção dos conceitos científicos em } \\
\text { aulas de ciências no estudo da sexualidade } \\
\text { humana. }\end{array}$ & $\begin{array}{l}\text { Universidade } \\
\text { Regional do } \\
\text { Noroeste do } \\
\text { Estado do Rio } \\
\text { Grande do Sul }\end{array}$ \\
\hline $\mathrm{D}_{3}$ Crepalde (2012) & $\begin{array}{l}\text { Da energia pensada à energia vivida: um diálogo } \\
\text { intercultural com as ciências }\end{array}$ & $\begin{array}{l}\text { Universidade } \\
\text { de São Paulo }\end{array}$ \\
\hline $\mathrm{D}_{4}$ Moura (2016) & $\begin{array}{l}\text { O ensino da teoria da evolução: a construção de } \\
\text { conceitos científicos }\end{array}$ & $\begin{array}{l}\text { Universidade } \\
\text { de São Paulo }\end{array}$ \\
\hline $\mathrm{T}_{2}$ Crepalde (2016) & $\begin{array}{l}\text { O discurso do outro na linguagem do outro: o } \\
\text { híbrido no desenvolvimento do conceito energia }\end{array}$ & $\begin{array}{l}\text { Universidade } \\
\text { Federal de } \\
\text { Minas Gerais }\end{array}$ \\
\hline
\end{tabular}


LOURENÇO, D. S. de WIRZBICKI, S. M.

\begin{tabular}{|c|c|c|}
\hline $\mathrm{D}_{5}$ Sena $(2016)$ & $\begin{array}{l}\text { Atividades mediadas como colaboração para } \\
\text { aprendizagem de conceitos científicos sobre } \\
\text { doenças epidêmicas }\end{array}$ & $\begin{array}{l}\text { Universidade } \\
\text { Tecnológica } \\
\text { Federal do } \\
\text { Paraná }\end{array}$ \\
\hline $\mathrm{D}_{6}$ Kierepka (2017) & $\begin{array}{c}\text { Problematização e reconhecimento de teorias e } \\
\text { práticas de professores em formação para o } \\
\text { ensino de ciências com foco no educar pela } \\
\text { pesquisa }\end{array}$ & $\begin{array}{l}\text { Universidade } \\
\text { de São Paulo }\end{array}$ \\
\hline $\mathrm{D}_{7}$ Amado (2017) & $\begin{array}{l}\text { Aprendendo a ouvir aqueles que não ouvem: o } \\
\text { desafio do professor de Ciências no trabalho com } \\
\text { a linguagem científica com alunos surdos }\end{array}$ & $\begin{array}{l}\text { Universidade } \\
\text { Federal de } \\
\text { Minas Gerais }\end{array}$ \\
\hline $\mathrm{D}_{8}$ Botelho (2017) & $\begin{array}{l}\text { O processo de ensino e aprendizagem de } \\
\text { conceitos científicos nos anos iniciais do Ensino } \\
\text { Fundamental na perspectiva vigotskiana e a } \\
\text { formação do pedagogo para o ensino de Ciências }\end{array}$ & $\begin{array}{l}\text { Universidade } \\
\text { Estadual } \\
\text { Paulista }\end{array}$ \\
\hline $\mathrm{D}_{9}$ Castro (2019) & $\begin{array}{l}\text { Impactos das discussões de professores sobre } \\
\text { aprendizagem com base no capítulo } 6 \text { de "a } \\
\text { construção do pensamento e da linguagem" }\end{array}$ & $\begin{array}{l}\text { Universidade } \\
\text { Federal do } \\
\text { Pampa }\end{array}$ \\
\hline $\mathrm{T}_{3}$ Carvalho (2019) & $\begin{array}{c}\text { Perguntas como mediação: apropriação de } \\
\text { conceitos científicos nos anos iniciais do Ensino } \\
\text { Fundamental }\end{array}$ & $\begin{array}{l}\text { Universidade } \\
\text { de São Paulo }\end{array}$ \\
\hline $\mathrm{T}_{4}$ Moraes (2019) & $\begin{array}{c}\text { Ensino-aprendizagem de conceitos científicos no } \\
\text { Ensino Médio na concepção da Teoria Histórico- } \\
\text { Cultural }\end{array}$ & $\begin{array}{c}\text { Pontifícia } \\
\text { Universidade } \\
\text { Católica do Rio } \\
\text { de Janeiro }\end{array}$ \\
\hline
\end{tabular}

Fonte: Elaboração própria (2020).

Assim, foram classificados, ao todo, 13 trabalhos - 9 dissertações e 4 teses - que serão identificados no decorrer do artigo como: $D_{1}$ Silva (2004); $D_{2}$ Ribeiro (2008);... $T_{1}$ Schroeder (2008) e assim sucessivamente. Esses trabalhos constituíram o corpus da análise que, segundo Moraes e Galiazzi (2007), é a matéria-prima do estudo e da investigação. Realizamos uma leitura minuciosa de cada dissertação e tese, com o objetivo de seguir as etapas previstas na ATD e identificar possíveis categorias de análise bem como novas compreensões acerca da temática.

Como característica própria da metodologia de análise adotada, primeiramente realizamos a desconstrução dos dados (unitarização). Nas palavras de Moraes e Galiazzi (2007, p. 10), a unitarização ou desconstrução do corpus de análise "[...] consistem num processo de desmontagem ou desintegração dos textos, destacando seus elementos constituintes". Dessa forma, realizamos recortes de excertos de cada uma das dissertações e teses, destacando as relações entre interações e formação de conceitos. Para desenvolver esses recortes foi necessário fazer uma leitura mais ampla dos trabalhos a fim de encontrar tais relações.

O segundo movimento realizado foi o da síntese (categorização). Para Moraes e Galiazzi (2007, p. 14), "[...] a categorização é um processo de comparação constante entre as unidades definidas no processo inicial da análise, levando a agrupamentos de elementos semelhantes". Nessa etapa da ATD definimos as unidades de sentido de cada um dos excertos do corpus de análise e chegamos a um total de 29 unidades. Essas unidades permitiram-nos agrupar os trabalhos em categorias: Iniciais, Intermediárias e 
Finais.

Na categorização Inicial as unidades de sentido constituíram 21 categorias; dessas, três constituíram as categorias Intermediárias, das quais somente duas compuseram a categorização Final, quais sejam: Interações no Ensino e aprendizagem de conceitos e $O$ papel da mediação no ensino e aprendizagem de conceitos.

Quadro 2 - Categorias Finais com a distribuição dos trabalhos

\begin{tabular}{|c|c|}
\hline \multicolumn{2}{|l|}{ Categorias Finais } \\
\hline Interações no ensino e aprendizagem de conceitos & $\begin{array}{c}\text { O papel da mediação no } \\
\text { ensino e aprendizagem de } \\
\text { conceitos }\end{array}$ \\
\hline $\begin{array}{c}D_{1} \text { Silva (2004); } D_{2} \text { Ribeiro (2008); } T_{1} \text { Schroeder (2008) } \\
D_{3} \text { (Crepalde, 2012); } D_{4} \text { Moura (2016); } T_{2} \text { Crepalde (2016); } D_{5} \\
\text { Sena (2016); } D_{6} \text { Kierepka (2017); } D_{7} \text { Amado (2017); } D_{8} \\
\text { Botelho (2017); } D_{9} \text { Castro (2019); } D_{10} \text { Carvalho (2019); } T_{3} \\
\text { Moraes (2019). }\end{array}$ & $\begin{array}{c}\mathrm{D}_{2} \text { Ribeiro (2008); } \mathrm{D}_{3} \text { Crepalde } \\
(2012) ; \mathrm{D}_{4} \text { Moura }(2016) ; \mathrm{D}_{5} \text { Sena } \\
\text { (2016); } \mathrm{D}_{9} \text { Amado }(2017) ; \mathrm{D}_{10} \\
\text { Carvalho (2019); } \mathrm{T}_{3} \text { Moraes } \\
\text { (2019). }\end{array}$ \\
\hline
\end{tabular}

Fonte: Elaboração própria (2020).

O último movimento da ATD foi o da descrição e interpretação, a fim de construir textos reorganizados (metatextos). Moraes e Galiazzi (2007, p. 96) definem o metatexto como escrita de um texto que é articulada a partir da categorização, considerando que "[...] a validade de um metatexto pode ser construída a partir da inserção no texto de falas e citações de fragmentos dos textos analisados, o que denominamos interlocuções empíricas". A partir desse movimento de análise é que construímos os resultados que são apresentados por meio da discussão das duas categorias Finais.

\section{INTERAÇÕES NO ENSINO E APRENDIZAGEM DE CONCEITOS}

Na construção deste metatexto buscamos explicitar o olhar dos autores das teses e dissertações para as interações no ensino e aprendizagem de conceitos e como essas compreensões estabelecem conexões com o referencial teórico Histórico-Cultural supracitado neste trabalho.

O termo "interações" pode estar relacionado a inúmeras expressões e contextos. Nos trabalhos que compuseram este metatexto, o termo está mais relacionado aos espaços de aprendizagem, e as interações mais evidenciadas são as que oorrem entre professor e aluno, aluno e professor e entre pares; interações expressas do tipo discursivas, orais, verbais e sociais.

O referencial teórico Histórico-Cultural (vigotskiano) defende que a aprendizagem ocorre em ambientes sociais de interação, e o adulto, ou alguém em uma fase mais avançada do desenvolvimento, é o responsável por transmitir toda a cultura. 
Ao entendermos a escola como espaço social e interacionista, compreendemos também que esse espaço de aprendizagem, quando não comunicativo, enfrenta dificuldades para promover o desenvolvimento conceitual dos alunos, pois as relações de interação fazem parte da cultura e da constituição dos sujeitos.

Compreender as interações no ensino e aprendizagem, como elas se organizam e como acontecem, leva-nos a refletir sobre as próprias razões da aprendizagem: qual seria o sentido do ensino se ele não fosse capaz de provocar inquietações nos alunos, trocas de diálogo e escuta? Nesse sentido, ao considerarmos a escola um espaço social e de constantes interações, a $\mathrm{T}_{1}$ traz que:

[...] a aprendizagem não acontece somente nas interações do indivíduo com o seu meio físico, mas, principalmente, por meio das interações sociais: alguém que aprende pressupõe alguém que ensina e é a escola o espaço socialmente organizado para a disseminação dos conhecimentos científicos (SCHROEDER, 2008, p. 30).

De tal modo, na $D_{2}$ Ribeiro (2008, p. 56), ao considerar a escola um espaço propício para a aprendizagem, destaca que "[...] nas interações escolares, as orientações para a aquisição de conhecimentos sistematizados pelos alunos, na maioria das vezes, são organizadas de maneira discursiva e lógico-verbal". O referido autor contribui ainda mencionando a importância do professor e de colegas mais experientes no desencadeamento dessas interações.

Nessa mesma perspectiva, na $D_{6}$ Kierepka (2017, p. 94) compreende que o conhecimento construído "[...] perpassa necessariamente pela interação entre professoraluno-objeto de conhecimento, pois a participação passiva do aluno no processo de ensino não gera significação conceitual". A aprendizagem conceitual necessita das interações dialógicas; do contrário ela é infecunda, e espaços de ensino monólogos de diálogo e ausentes de empatia não promovem o desenvolvimento do estudante.

Já na $\mathrm{T}_{2}$ Crepalde (2016) destaca a importância do contexto de ensino e aprendizagem conceitual e as interações entre pares envolvidas nesse processo. Para o autor, "[...] o contexto de interação entre pares pode proporcionar respostas mais refletidas, ou até mesmo a construção de conclusões e novos questionamentos que outro método não proporcionaria" (CREPALDE, 2016, p. 83).

Como, então, desencadear interações e romper com as barreiras do discurso monológico do professor? Primeiramente há de se considerar que nenhum aluno vem despido de qualquer tipo de conhecimento para a escola; ele carrega consigo uma história e uma cultura. Considerar esses aspectos é essencial na aprendizagem. Essas particularidades podem ser exploradas pelo professor quando este problematizar os conhecimentos espontâneos trazidos pelos sujeitos. Com isso, é possível estabelecer relações entre o que o aluno já sabe e o que ele ainda é capaz de aprender. Para Fontana (1997, p. 124), “[...] a relação da criança com o conceito é sempre mediada por outro conceito".

Deste modo, na $D_{3}$, o autor afirma que "o desenvolvimento dos conceitos pode ser compreendido como relação e interação entre os conceitos cotidianos e científicos" (CREPALDE, 2012, p. 59). Numa perspectiva mais profunda de diferenciação entre os conceitos, na $\mathrm{D}_{9}$ Castro (2019) destaca que, 


\begin{abstract}
Há uma notória diferença, portanto, entre os dois conceitos, na medida em que o espontâneo, como o próprio nome expressa, nasce da experiência concreta e não formal, enquanto o científico, também como o indica a nomenclatura, direciona-se especificamente aos conhecimentos obtidos de forma sistematizada e nas sendas das interações propiciadas no ensino formal (CASTRO, 2019, p. 40).
\end{abstract}

Nesse sentido, as atividades sistematizadas favorecem o desenvolvimento conceitual do aluno, que é sempre impulsionado pela aprendizagem e pelas interações estabelecidas. Tal afirmação vai ao encontro das concepções expressas por Rego (2013, p. 78), quando assevera que "[...] os conceitos científicos estão integrados às situações sistematizadas e adquiridas nas interações sociais".

Dessa forma, há de se considerar que um bom planejamento e sistematização das atividades contribui para que interações aconteçam. Souza e Maldaner (2012) destacam que o planejamento do ensino, quando bem adequado e que considere a realidade do sujeito, contribui para o desenvolvimento conceitual deste, possibilitando novas funções mentais. Daí a importância do professor e dos elementos mediadores nesse processo. $\mathrm{Na} \mathrm{D}_{4}$ Moura (2016) descreve que

[...] os professores, as ferramentas semióticas e a própria lógica da instituição escolar realizam intervenções no universo de significados trazidos pelas crianças e concebe-se então um campo de interação, desafio, negociação de significados, questionamento, fundamental ao processo de desenvolvimento conceitual (MOURA, 2016, p. 17).

$\mathrm{Na} D_{5}$ Sena (2016, p. 19) assevera que "[...] para a formação dos conceitos científicos é preciso compreender o processo de internalização". Numa perspectiva vigotskiana (VIGOTSKI, 2009), isso requer entender como o conhecimento externo, construído em meio social e interacionista, é internamente apropriado e reconstruído pelo sujeito. Desse modo, na $\mathrm{D}_{8}$ Botelho (2017) expõe que:

[...] o desenvolvimento dos conceitos científicos é um processo ativo, de ação, mediação, relação e interação, no qual o sujeito suplanta sua passividade sensível diante do mundo material vivido e passa a abstrair em sua mente os dados empíricos a fim de generalizá-los, formando conceitos científicos a partir dos conceitos espontâneos restritos à superficialidade da palavra ainda carente do significado pleno (BOTELHO, 2017, p. 88).

O processo de internalização e apropriação dos conceitos científicos demanda uma série de estímulos mentais que vão se desencadeando a partir da mediação. Quando o professor consegue fazer bom uso dos elementos mediadores, signos e instrumentos, o desenvolvimento conceitual do aluno atinge maior êxito. $\mathrm{Na} \mathrm{D}_{1}$ Silva (2004, p. 1) compreende também a importância do planejamento, da aplicação e da 
sistematização dos conceitos no processo de ensino "[...] para que a aprendizagem de conceitos científicos se dê de forma satisfatória, por meio da aquisição de um sistema de significados formados por conceitos com alto grau de generalidade e consciência".

Assim, a perspectiva Histórico-Cultural considera que a utilização de signos altera essencialmente os processos psicológicos, enquanto o uso de instrumentos amplifica as possibilidades de aprendizagem, propiciando e inovando as habilidades mentais (SILVA, 2013). $\mathrm{Na} \mathrm{T}_{3}$ Carvalho (2019) defende a importância do questionamento para promover o avanço conceitual do aluno, pois, quando o professor faz uso da palavra para elaborar perguntas ao estudante, ele está estimulando o desenvolvimento das funções mentais superiores, como a fala, o pensamento, a memória mediada e a atenção dirigida. Essas funções atribuem sentido à aprendizagem, uma vez que $T_{4}$ Moraes (2019, p. 57), ao discorrer sobre as funções mentais superiores, afirma que "[...] a aprendizagem é responsável diretamente por promover o desenvolvimento".

Neste metatexto, compreendemos que as interações professor e aluno, alunoaluno, do tipo verbais, orais e discursivas, são as mais utilizadas para trabalhar o desenvolvimento conceitual do estudante em sala de aula. Em relação ao estudo dos conceitos científicos, é apontada a importância da sistematização das atividades elaboradas pelo professor, considerando o contexto em que o estudante está inserido. No próximo metatexto discutiremos o que algumas dessas pesquisas trazem sobre o papel da mediação no ensino e aprendizagem de conceitos científicos.

\section{O PAPEL DA MEDIAÇÃO NO ENSINO EAPRENDIZAGEM DE CONCEITOS}

Nesta categoria procuramos reunir aspectos trazidos pelos pesquisadores sobre o papel da mediação no ensino e aprendizagem de conceitos, estabelecendo relações entre o professor, o estudante e o objeto de conhecimento.

Na perspectiva vigotskiana (VIGOTSKI, 2009), a escola é um ambiente de interação social e também de produção de conhecimento, sendo a mediação um processo fundamental no ensino e aprendizagem, uma vez que ela estabelece um elo entre o professor, o aluno e o objeto de conhecimento, num movimento colaborativo e de constantes interações. $\mathrm{Na} \mathrm{T}_{3}$ Carvalho (2019) concebe que:

[...] a mediação, caracteriza-se, portanto, como uma base propulsora das relações sociais e culturais intrínsecas ao percurso do desenvolvimento humano, e os processos psicológicos que tem relação com a apropriação de significados, que não são lineares (CARVALHO, 2019, p. 65).

Deste modo, há de se considerar que a aprendizagem não ocorre de forma direta, mas por meio de elementos mediadores, os signos e os instrumentos, que, apesar de serem distintos, estão intimamente interligados e se complementam no processo de ensino e aprendizagem. $\mathrm{Na} \mathrm{T}_{3}$ Moraes (2019) destaca que:

[...] um dos pressupostos mais importantes da Teoria HistóricoCultural é de que a passagem da atividade prática dos animais à atividade humana ocorre pela mediação de meios externos, sendo os mais importantes os instrumentos e os signos, com a intenção de 
satisfazer certas necessidades. Sob essa perspectiva, tanto os instrumentos quanto os signos são produtos da cultura e agem como mediadores entre o homem e o mundo (MORAES, 2019, p. $18)$.

Destarte, na perspectiva de Vigotski (2009), a palavra é um signo mediador, que se mostrou nesta pesquisa muito utilizada pelo professor de forma oral, verbal e discursiva, contribuindo para o fomento de interações. $\mathrm{Na} \mathrm{T}_{3}$ Moraes (2019, p. 18) salienta que "[...] a palavra é o mais importante dos signos, pois constitui o principal meio de relação entre os seres humanos". Em se tratando do uso da palavra no ensino e aprendizagem de conceitos, a afirmação de Moraes (2019), na $T_{3}$, vai ao encontro dos estudos desenvolvidos por Vigotski (2009, p. 170), que, em uma passagem, ressalta:

[...] o conceito é impossível sem palavras, o pensamento em conceitos é impossível fora do pensamento verbal, em todo esse processo, o momento central que tem todos os seus fundamentos para ser considerado causa decorrente para o amadurecimento dos conceitos é o emprego específico da palavra, o emprego funcional do signo como meio de formação de conceitos (VIGOTSKI, 2009, p. 170).

Nessa mesma direção, os instrumentos, na visão de Vigotski (2009), auxiliam nas funções concretas da aprendizagem ao possibilitarem o acesso do estudante ao objeto de conhecimento. Para o professor, o uso de instrumentos didático-pedagógicos é imprescindível, uma vez que eles contribuem na condução das suas atividades sistematizadas. $\mathrm{Na}_{5}$ Sena $(2016$, p. 66) assevera que "[...] os instrumentos fazem parte da atividade mediada atuando sobre a ação dos indivíduos, e quando em conjunto com a atividade de signos, geram as funções superiores mentais".

Refletindo sobre a mediação no processo de ensino e aprendizagem de conceitos científicos, reconhecemos o papel de destaque do professor, pois, ao se apropriar e fazer uso dos elementos mediadores, dos signos e dos instrumentos, ele garante melhores condições para promover a interatividade do estudante e instigar seu senso crítico e a capacidade de equilíbrio em lidar com os conflitos cognitivos, pois isso contribui para o seu desenvolvimento conceitual e para a constituição autônoma dos sujeitos. Ao trabalhar o desenvolvimento de conceitos científicos e se questionar sobre a mediação do professor nesse processo, Moraes (2019, p. 181), em T T $_{3}$ destaca que,

[...] assim, o movimento de transição do concreto para o abstrato não é mais fácil do que a transição do abstrato para o concreto. Entendemos que a mediação do professor é essencial para estabelecer esse movimento, através da apresentação de questões problemas aos estudantes que os levem a relacionar os conceitos científicos às questões da vida concreta (MORAES, 2019, p. 181).

Ao se apropriar dos elementos mediadores, o professor desempenha um papel importante no desenvolvimento conceitual do aluno, pois, para Schnetzler, Silva e 
Antunes-Souza (2016, p. 15), “[...] os conceitos científicos no contexto escolar são apropriados e reelaborados na interação professor-aluno pela mediação pedagógica". $\mathrm{Na} \mathrm{D}_{4}$, Amado (2017, p. 84-85) vai ao encontro das autoras e acrescenta que "[...] o professor deve estar constantemente exercendo o papel de mediador para que, nessa construção, não ocorram equívocos conceituais".

Tal compreensão trazida na $\mathrm{D}_{4}$ é importante, uma vez que o estudante já vem para a sala de aula com uma bagagem de conhecimento adquirida em suas vivências empíricas que precisa ser polida pelo professor no objetivo de contribuir para que esse estudante atinja uma compreensão conceitual mais avançada. Na tentativa de evitar quaisquer equívocos conceituais, é sempre bom lembrar o que Fontana (1997, p. 124) apresenta sobre a aprendizagem conceitual: "[...] a relação da criança com o conceito é sempre mediada por outro conceito".

Daí a importância da mediação docente nos processos metodológicos que vão orientando o estudante a relacionar conceitos com seus conhecimentos prévios. Nessa mesma linha de compreensão, na $D_{8}$ Crepalde (2012, p. 131) afirma que "[...] cada aluno com a ajuda da mediação do professor contribui na tomada de consciência dos seus colegas ao explicitar, acrescentar e até mesmo contrastar sentidos".

Nesse sentido, o uso da palavra, como signo mediador, é imprescindível, pois, por intermédio dela, o professor vai estabelecendo relações entre o aluno e o objeto de conhecimento, e isso contribui para que a aprendizagem ocorra em meio à interatividade dos sujeitos envolvidos. Desse modo, na $D_{2}$ Ribeiro (2008) destaca que

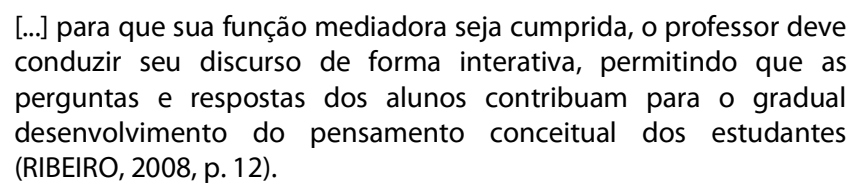
conduzir seu discurso de forma interativa, permitindo que as perguntas e respostas dos alunos contribuam para o gradual desenvolvimento do pensamento conceitual dos estudantes (RIBEIRO, 2008, p. 12).

Os argumentos dos autores nos levam a compreender que o desenvolvimento conceitual do aluno está relacionado à mediação em sala de aula, posto que a palavra é indicada como o principal signo mediador da aprendizagem. O corpus de análise aponta para a importância do professor nos processos mediados, destacando que a mediação está relacionada à interatividade do estudante, e que o professor só consegue mediar conceitos quando seu estudante contribui, trazendo suas vivências para a sala de aula, que podem ser usadas para criar relações com o objeto de conhecimento e serem discutidas e problematizadas. Por sua vez, o estudante somente traz vivências para a sala de aula quando o professor tem consciência de que esse espaço de aprendizagem não pertence somente a ele, mas a todos que se colocam na condição de aprendizes.

\section{CONSIDERAÇÕES FINAIS}

O estudo sobre as interações no ensino e aprendizagem de conceitos indica que as interações aluno e professor, professor e aluno e entre pares são as mais recorrentes em sala de aula, do tipo discursivas, orais, verbais e sociais. Evidenciamos, também, que a aprendizagem dos conceitos científicos acontece mediante interações, e o professor desenvolve um protagonismo importante nesse processo, que, por meio dos 
elementos mediadores, como os signos e instrumentos, impulsiona o desenvolvimento conceitual do estudante.

Os resultados permitem-nos afirmar que as interações influenciam para o desenvolvimento conceitual dos estudantes ao atribuírem participação ativa/interativa no processo de aprendizagem, seja por meio da interação com o professor e/ou também com seus colegas, sendo a palavra reconhecida pelo corpus de análise como o principal signo mediador nos processos educativos.

O desenvolvimento das funções mentais superiores no corpus de análise é relacionado aos estímulos cognitivos provocados pelo professor em sala de aula, uma vez que está sempre em condição de se desenvolver. As interações com o professor, com colegas e/ou com outros indivíduos, aliados à mediação, são elementos que potencializam o desenvolvimento humano e determinam a aprendizagem. Na ausência dos processos mediados não há interação. Sem interagir o indivíduo não tem estímulos, e sem estímulos não há aprendizagem. Precisamos estar sempre respondendo aos estímulos para nos desenvolver. Isso não é diferente no ensino. Os sujeitos desenvolvem-se pelos estímulos provocados em seu meio, nas interações sociais e na relação com o outro, sendo o professor, assegurado pelos elementos mediadores, um dos principais responsáveis em garantir esse processo.

Dessa forma, este estudo leva-nos a compreender que as interações estão presentes nos processos mediados e a mediação requer o estabelecimento de interações. Ambos os processos são inter-relacionados e se complementam em sua plenitude, seja contribuindo para o desenvolvimento e a compreensão conceitual do estudante, seja formando sujeitos críticos e autônomos com capacidade de compreender o conhecimento científico para além da sala de aula.

Artigo recebido em: 18/08/2020 Aprovado para publicação em: 23/11/2020 INTERACTIONS AND FORMATION OF CONCEPTS IN SCIENCES: A LOOK AT BRAZILIAN RESEARCH IN
THE LIGHT OF THE HISTORICAL-CULTURAL THEORETICAL FRAMEWORK

ABSTRACT: The proposed work aims to present how scientific production in the area of Science and Biology teaching has included the conceptual formation of students and what interactions characterize this learning process. From a methodological point of view, it is a qualitative research, with a descriptive and bibliographic character. For data analysis, Textual Discourse Analysis (DTA) procedures were used. From the analysis it was possible to identify the emerging categories Interactions in the Teaching and learning of concepts and the role of mediation in the teaching and learning of concepts. The consulted works bring the use of the word as the main mediating sign of learning. The most frequent interactions pointed out are those between teacher and student, student and teacher and between peers. 
LOURENÇO, D. S. de WIRZBICKI, S. M.

KEYWORDS: Science and Biology Teaching. Mediation. Conceptual Understanding. Cultural Historical Theory.

INTERACCIONES Y FORMACIÓN DE CONCEPTOS EN CIENCIAS: UNA MIRADA A LA INVESTIGACIÓN BRASILEÑA A LA LUZ DEL MARCO TEÓRICO HISTÓRICO-CULTURAL

RESUMEN: El trabajo propuesto tiene como objetivo presentar cómo la producción científica en el área de la enseñanza de las Ciencias y la Biología ha incluido la formación conceptual de los estudiantes y qué interacciones caracterizan este proceso de aprendizaje. Desde el punto de vista metodológico, se trata de una investigación cualitativa, de carácter descriptivo y bibliográfico. Para analizar los datos se utilizaron procedimientos de Análisis de Texto Discursivo (DTA). A partir del análisis fue posible identificar las categorías emergentes Interacciones en la enseñanza y aprendizaje de conceptos y El papel de la mediación en la enseñanza y aprendizaje de conceptos. Las obras consultadas traen el uso de la palabra como principal signo mediador del aprendizaje. Las interacciones más recurrentes señaladas son entre profesor y alumno, alumno y profesor y entre compañeros.

PALABRAS CLAVE: Enseñanza de Ciencias y Biología. Mediación. Comprensión conceptual. Teoría histórica cultural.

\section{REFERÊNCIAS}

AMADO, B. C. Aprendendo a ouvir aqueles que não ouvem: o desafio do professor de Ciências no trabalho com a linguagem científica com alunos surdos. 2017. Dissertação (Mestrado em Ensino de Ciências) - Faculdade de Educação, Universidade de São Paulo, São Paulo, 2017. Disponível em: https://www.teses.usp.br/teses/disponiveis/81/81133/tde-05072018-

141511/publico/Beatriz_Crittelli_Amado.pdf. Acesso em: 24 nov. 2020.

BOTELHO, R. O processo de ensino e aprendizagem de conceitos científicos nos anos iniciais do Ensino Fundamental na perspectiva vigotskiana e a formação do pedagogo para o ensino de Ciências. 2017. Dissertação (Mestrado em Educação para a Ciência) - Faculdade de Ciências, Universidade Estadual Paulista, Bauru, SP, 2017. Disponível em: https://repositorio.unesp.br/bitstream/handle/11449/150886/botelho_r_me_bauru.pdf? sequence=3\&isAllowed=y. Acesso em: 24 nov. 2020.

BRASIL. Base Nacional Comum Curricular. Brasília: MEC, 2017. Disponível em: http://basenacionalcomum.mec.gov.br/images/BNCC_El_EF_110518_versaofinal_site.p df . Acesso em: 22 maio 2020.

CARVALHO, M. S. de. A. Perguntas como mediação: apropriação de conceitos científicos nos anos iniciais do Ensino Fundamental. 2019. Tese. (Doutorado em 
Educação) - Faculdade de Educação, Universidade de São Paulo, São Paulo, 2019. Disponível em: https://teses.usp.br/teses/disponiveis/48/48134/tde-23052019181003/publico/MARIANA_SALES_DE_ARAUJO_CARVALHO_rev.pdf. Acesso em: 24 nov. 2020.

CASTRO, N. N. Impactos das discussões de professores sobre aprendizagem com base no capítulo 6 de "A construção do pensamento e da linguagem". 2019. Dissertação (Mestrado Profissional em Educação) - Faculdade de Educação, Universidade Federal do Pampa, Jaguarão, SP, 2019. Disponível em: http://dspace.unipampa.edu.br:8080/jspui/bitstream/riu/4589/1/NandjaraNovoCastro20 19.pdf. Acesso em: 24 nov. 2020.

CREPALDE, R. dos S. Da energia pensada à energia vivida: um diálogo intercultural com as ciências. 2012. Dissertação (Mestrado em Conhecimento e Inclusão Social em Educação) - Faculdade de Educação, Universidade Federal de Minas Gerais, Belo Horizonte, 2012. Disponível em: https://repositorio.ufmg.br/bitstream/1843/BUOS8TXLKM/1/disserta_o_rodrigo_dos_santos_crepalde.pdf. Acesso em: $20 \mathrm{abr} .2020$.

CREPALDE, R. dos S. O discurso do outro na linguagem do outro: o híbrido no desenvolvimento do conceito energia. 2016. Tese (Doutorado em Conhecimento e Inclusão Social em Educação) - Faculdade de Educação, Universidade Federal de Minas Gerais, Belo Horizonte, 2016. Disponível em: https://repositorio.ufmg.br/bitstream/1843/BUBD-

ADQL5X/1/tese_rodrigo_dos_santos_crepalde.pdf . Acesso em: 20 abr. 2020.

FONTANA, R. A. C. Mediação pedagógica em sala de aula. Campinas: Editora Autores Associados, 1997.

GÓES, M. C. R. As relações intersubjetivas na construção de conhecimentos. In: GÓES, M. C.; SMOLKA, A. L. B. (org.). A significação nos espaços educacionais: interação social e subjetivação. Campinas: Papirus, 1997. p. 11-45

KIEREPKA, J. S. N. Problematização e reconhecimento de teorias e práticas de professores em formação para o ensino de Ciências com foco no educar pela pesquisa. 2017. Dissertação (Mestrado em Ensino de Ciências) - Faculdade de Educação nas Ciências, Universidade Regional do Noroeste do Estado do Rio Grande do Sul, ljuí, RS, 2017. Disponível em:

https://bibliodigital.unijui.edu.br:8443/xmlui/bitstream/handle/123456789/5127/Janice \%20Silvana\%20Novakowski\%20Kierepka.pdf?sequence=1\&isAllowed=y. Acesso em: 20 abr. 2020.

LÜDKE, M.; ANDRÉ, M. E. D. A. Pesquisa em educação: abordagens qualitativas. 2. ed. São Paulo: EPU, 1986. 


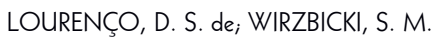

MORAES, R. M. de. Ensino-aprendizagem de conceitos científicos no Ensino Médio na concepção da Teoria Histórico-Cultural. 2019. Tese (Doutorado em Educação) Faculdade de Educação, Pontifícia Universidade Católica do Rio de Janeiro, Rio de Janeiro. Disponivel em: https://www.maxwell.vrac.puc-rio.br/46754/46754.PDF. Acesso em: 24 nov. 2020.

MORAES, R.; GALIAZZI, M do. C. Análise Textual Discursiva. 2. ed. ljuí: Editora Unijuí, 2007.

MOURA. S. F. de. O ensino da teoria da evolução: a construção de conceitos científicos. 2016. Dissertação (Mestrado em Educação em Ciências e Matemática) - Faculdade de Educação, em Ciências e Matemática, Universidade Federal de Goiás, Goiânia, 2016. Disponível em: https://repositorio.bc.ufg.br/tede/bitstream/tede/6808/5/Disserta\%c3\%a7\%c3\%a3o\%20 -\%20Susana\%20Ferreira\%20de\%20Moura\%20-\%202016.pdf. Acesso em: 20 abr. 2020.

REGO, T. C. Vygotsky: uma perspectiva histórico-cultural da educação. 24. ed. Petrópolis: Vozes, 2013.

RIBEIRO, A. C. Interações discursivas e elaboração de conteúdos científicos no Ensino Médio. 2008. Dissertação (Mestrado em Educação para a Ciência e o Ensino de Matemática) - Faculdade de Ciências Exatas e Tecnológicas, Universidade Estadual de Maringá, Maringá, 2008. Disponível em: http://repositorio.uem.br:8080/jspui/bitstream/1/4458/1/000166283.pdf. Acesso em: 20 abr. 2020.

SANTOS, M. B. Escrever, para quê?! A redação mediando a formação de conceitos. Revista Inter Ação, Goiânia, v. 26, n. 2, p. 1-15, 31 ago. 2007.

SCHNETZLER, R. P.; SILVA, L. E. A.; ANTUNES-SOUZA, T. Mediações pedagógicas na interpretação de experimentações investigativas: uma estratégia didática para a formação docente em química. Revista Inter Ação, Goiânia, v. 41, n. 3, p. 585-604, 19 dez. 2016.

SCHROEDER, E. A. A teoria histórico-cultural do desenvolvimento como referencial para análise de um processo de ensino: a construção dos conceitos científicos em aulas de ciências no estudo da sexualidade humana. 2008. Tese (Doutorado em Educação Científica e Tecnológica) - Faculdade de Ciências ds Educação, Universidade Federal de Santa Catarina, Florianópolis, 2008. Disponível em: http://repositorio.ufsc.br/xmlui/handle/123456789/91453. Acesso em: 20 abr. 2020.

SENA, J. Y. de. Atividades mediadas como colaboração para aprendizagem de conceitos científicos sobre doenças epidêmicas. 2016. Dissertação (Mestrado em Ensino de Ciências Humanas, Sociais e da Natureza) - Faculdade de Educação, Universidade Tecnológica Federal do Paraná, Londrina, PR, 2016. Disponível em: 
http://repositorio.utfpr.edu.br/jspui/bitstream/1/1668/1/LD_PPGEN_M_Sena\%2c\%20Jul iana\%20Yporti\%20de_2016.pdf. Acesso em: 24 nov. 2020.

SILVA, D. V. C. Análise do desenvolvimento de conceitos científicos sobre a teoria da evolução das espécies em alunos do Ensino Médio. 2004. Dissertação (Mestrado em Educação) - Faculdade de Educação e Ciências Humanas, Universidade Federal de São Carlos, Centro de Educação e Ciências Humanas, São Carlos, 2004. Disponível em: https://repositorio.ufscar.br/bitstream/handle/ufscar/2540/419.pdf?sequence=1\&isAllo wed=y. Acesso em: 20 abr. 2020.

SILVA, L. H. A. A perspectiva histórico-cultural do desenvolvimento humano: ideias para estudo e investigação do desenvolvimento dos processos cognitivos em ciências. In: GULLICH, R. I. C. (org.). Didática das Ciências. Curitiba: Prismas, 2013. p. 11-35.

SMOLKA, A. L. B. O (im)próprio e o (im)pertinente na apropriação das práticas sociais. Caderno Cedes, Campinas, v. 20, n. 50, p. 26-40, abr. 2000.

SOUZA, F. B. A.; MALDANER. O. A. Significação conceitual no início da escolarização das crianças. In: ENCONTRO DA PESQUISA EM EDUCAÇÃO DA REGIÃO SUL - ANPED/SUL, 9., 2012. Caxias do Sul, RS. Anais eletrônicos [...]. Disponível em: http://www.ucs.br/etc/conferencias/index.php/anpedsul/9anpedsul/paper/viewFile/206 /344. Acesso em: 22 maio 2020.

VIGOTSKI, L. S. A construção do pensamento e da linguagem. 2. ed. Tradução Paulo Bezerra. São Paulo: Martins Fontes, 2009.

WIRZBICKI, S.; DEL PINO, J.; PANSERA-DE-ARAÚJO, M. O conceito energia nas interações entre professores e estudantes mediadas pelos livros didáticos de biologia. Revista Insignare Scientia - RIS, Cerro Largo-RS, v. 2, n. 1, p. 138-150, 20 maio 2019.

DANIELA Silva de LOURenço: Licenciada em Ciências Biológicas pela Universidade Federal da Fronteira Sul - UFFS, Campus de Cerro Largo/RS. Possui Especialização Lato Sensu em Orientação Educacional pela UFFS, Campus de Cerro Largo/RS. Atualmente é mestranda do Programa de Pós-Graduação em Ensino de Ciências - PPGEC, na mesma instituição.

Orcid: https://orcid.org/0000-0001-8230-6510

E-mail: danieladelourenco@hotmail.com

SANDRA MARIA WIRZBICKI: Doutora em Educação em Ciências pela Universidade Federal do Rio Grande do Sul (UFRGS). Mestre em Educação nas Ciências e Licenciada em Ciências Biológicas pela Universidade Regional do Noroeste do Estado do Rio Grande do Sul (UNIJUÍ). Atualmente é Professora Adjunta da área de Ensino de Biologia no 
LOURENÇO, D. S. de WIRZBICKI, S. M.

curso de Licenciatura em Ciências Biológicas da Universidade Federal da Fronteira Sul (UFFS) - Campus Realeza, com atuação nos estágios curriculares supervisionados, metodologia e práticas de Ensino.

ORCID: https://orcid.org/0000-0001-8402-7099

E-mail:sandra.wirzbicki@uffs.edu.br

Este periódico utiliza a licença Creative Commons Attribution 3.0, para periódicos de acesso aberto (Open Archives Iniciative - OAI). 